2

5

6

$$
7
$$
8

9

10

11

12

13

14

15

16

17

18

19

20

21

22

23

24

25

26

27

28

29

30 *Corresponding Author: Dr Gareth Williams (g.williams@ucl.ac.uk)

a UCL School of Pharmacy, University College London, London WC1N 1AX, UK UK

(1)

.$$
28
$$

\title{
Inhibiting the fibrillation of a GLP-1-like peptide
}

b Dosage Form Design and Development, AstraZeneca, Granta Park, Cambridge CB21 6GH, 


\section{Abstract}

33 Aggregation, including the formation of fibrils, poses significant challenges for the 34 development of therapeutic peptides. To develop stable peptide formulations, some 35 understanding of the mechanisms underpinning the fibrillation process is required. A thioflavin 36 T fluorescence assay was first used to determine the fibrillation profile of a GLP-1-like peptide 37 (G48) at conditions being considered to formulate the peptide. G48 concentrations ranged 38 from $0-600 \mu \mathrm{M}$ and three $\mathrm{pH}$ values $(\mathrm{pH} 3.7,7.4$ and 8.5) were evaluated. Kinetic data 39 demonstrate that $\mathrm{G} 48$ displays a $\mathrm{pH}$-dependent aggregation profile. At $\mathrm{pH} 3.7$, which is below 40 the isoelectric point of $\mathrm{G} 48$ ( $\mathrm{pl} \sim 5$ ), kinetics representative of amorphous aggregates forming 41 via a nucleation-independent mechanism were seen. At $\mathrm{pH} 7.4$ and $8.5(\mathrm{pH}>\mathrm{pl})$ typical 42 nucleation-dependent aggregation kinetics were observed. The weight concentration of $\beta$ 43 sheet rich aggregates ( $F L_{\max }$ ) correlated inversely with net charge, so lower $F L_{\max }$ values were 44 observed at $\mathrm{pH} 3.7$ and 8.5 than at $\mathrm{pH}$ 7.4. Incorporation of a non-ionic surfactant (polysorbate 45 80) into the peptide solution suppressed the fibrillation of $\mathrm{G} 48$ at all $\mathrm{pH}$ values and maintained 46 the native peptide conformation, whereas a phenolic co-formulant (ferulic acid) had minimal 47 effects on fibril growth. Peptide fibrillation, which can occur within a range of formulation 48 concentrations and $\mathrm{pH}$ values, can hence be inhibited by the judicious use of excipients. 


\section{Introduction}

51 Peptides serve many bio-functional roles and are widely used in medicine. There are over 70 peptides used clinically and a further 150 in clinical development [1]. One field in which peptide therapeutics have been successfully employed is endocrinology, particularly for the treatment of diabetes. Two such examples are insulin and glucagon-like peptide (GLP-1) agonists.

It is well established that compared to low molecular weight chemical entities, peptides face a greater number of challenges in drug development. One major issue is aggregation arising from the non-covalent association of individual molecules [2]. Peptides are capable of undergoing a specific type of aggregation leading to the formation of highly ordered $\beta$-sheet rich structures called fibrils [3]. While nature appears to have a handful of cases where fibrils play a functional role (such as mediation of binding to a host protein (Curlin, E. coli)) [4], in humans fibril growth is mostly implicated in morbidity such as Alzheimer's disease [5], amyloidosis [6], and nephropathy [7]. Reports have shown that the injection of preformed fibrils could potentially hasten amyloidosis [8]. Clinically used peptides generally have a shelf-life of two years, and only by understanding the mechanisms behind the fibrillation process can we develop formulations capable of maintaining stability throughout manufacturing, handling and patient usage. Moreover, an understanding of the mechanistic basics of fibril formation can inform early pre-formulation research.

The most widely accepted mechanism for the formation of peptide fibrils is nucleationdependent polymerisation, which can be broken down into three phases: (i) the lag phase, an initial period resulting in the formation of primary nuclei and barely detectable aggregates; ii) an exponential growth phase, during which secondary nuclei formation occurs and a high proportion of detectable $\beta$-sheet aggregates are generated; iii) a plateau phase where monomeric peptide become depleted and equilibrium between monomeric peptide and fibrils is reached [9-11]. Thioflavin T (ThT) is used as a probe for this process, because its increase in fluorescence upon binding to fibrils [12] allows the kinetics of their formation to be monitored. Myriad factors influence fibrillation propensity including peptide concentration, temperature, agitation and $\mathrm{pH}[2,13]$. Given the ionisable nature of peptides, the promotion of aggregation by changes in solution $\mathrm{pH}$ are particularly important $[14,15]$.

The majority of fibrillation studies focus on $\beta$-amyloid, and aside from insulin very few reports focus on providing insights into the fibril formation of clinically relevant peptides. With regard to formulation approaches for stabilising therapeutic peptides, there exist even fewer reports [16]. Nonetheless, formulation approaches are generally the most preferable approach for stabilising proteins and peptides as they obviate the need for further sequence modification or conjugation [17], which may alter the efficacy of the drug [2]. Two examples of excipients 
which are used to stabilise biotherapeutics are (i) phenols in insulin [18] and (ii) surfactants in antibody formulations [19].

Kinetic monitoring with ThT across a range of concentrations $(0-600 \mu \mathrm{M})$ was used in this study to quantify fibril formation by a GLP-1-like peptide of pharmaceutical interest (G48) at different $\mathrm{pH}$ values. The G48 fibrils were then characterised by circular dichroism (CD), reverse phase high performance liquid chromatography (RP-HPLC), dynamic light scattering (DLS), atomic force microscopy (AFM) and transmission electron microscopy (TEM). A mechanism for the $\mathrm{pH}$-dependent alteration in fibril kinetics for G48 is proposed. In addition, the influence of phenol (ferulic acid, FA) and surfactant (polysorbate 80, PS80) excipients on G48 fibrillation was also investigated.

\section{Materials and methods}

\subsection{Materials}

Peptide G48 is a linear peptide composed of 29 amino acid (AA) residues with a molecular weight (MW) of $~ 3.5 \mathrm{kDa}$ and an isoelectric point $(\mathrm{PI})$ of $\sim 5$ (estimated based on ionisable groups). G48 was provided by AstraZeneca (Cambridge, UK) with $>98 \%$ purity determined by RP-HPLC analysis. Thioflavin T (ThT), trisaminoethane (Tris), sodium hydroxide ( $\mathrm{NaOH})$, hydrochloric acid ( $\mathrm{HCl})$, ferulic acid (FA), trifluoroacetic acid (TFA), HPLC-grade acetonitrile and water were obtained from Fisher Scientific (Loughborough, UK). Sodium azide $\left(\mathrm{NaN}_{3}\right)$, sodium acetate and polysorbate 80 (PS80) were purchased from Sigma Aldrich (Gillingham, UK).

\subsection{Aggregation kinetics}

Stock solutions of G48 (1.2 $\mathrm{mM}$ ) were prepared in two different buffers at $\mathrm{pH}$ values ranging from 3.7 to 8.5: i) $\mathrm{pH} 3.7$ (acetate, $20 \mathrm{mM}$ ) and ii) pH 7.4 and pH 8.5 (Tris, $20 \mathrm{mM}$ ). From the stock solutions, serial dilutions gave a range of G48 concentrations $(600,300,150,75$, and $37.5 \mu \mathrm{M})$. Along with ThT $(50 \mu \mathrm{M})$ and $0.01 \% \mathrm{NaN}_{3}$ (preservative) at the appropriate $\mathrm{pH}$, samples of the peptide were added to a Greiner Bio black 96 well plate with transparent bottom (Kremsmünster, Germany). All solutions were initially filtered with a $0.22 \mu \mathrm{m}$ filter before use and the $\mathrm{pH}$ of individual wells was confirmed with a calibrated Hannah $\mathrm{pH}$ meter (Leighton Buzzard, UK) at the start and end of the kinetic study. The plates were sealed with aluminium foil to prevent evaporation and then incubated at $37^{\circ} \mathrm{C}$. At excitation and emission wavelengths of $440 \mathrm{~nm}$ and $480 \mathrm{~nm}$ respectively, fluorescence readings were recorded from the bottom of the plates every 30 mins on a Spectramax m2e plate reader (San Jose, California, USA) over four days, with $300 \mathrm{~s}$ of agitation at 250 RPM applied before each reading. Data collection was done with automatic cut-off and low photomultiplier tube (PMT) 
gain. In addition, seeding experiments were carried out by sonicating preformed aggregates at the appropriate $\mathrm{pH}$ for $350 \mathrm{~s}$, inoculating these at $5 \%$ vol/vol into G48 solutions (150 $\mu \mathrm{M})$ and then repeating the experiments described above. Three replicate experiments were conducted at each $\mathrm{pH}$ value. The aggregation kinetics were determined by fitting a Boltzman sigmoidal function onto the data set, and using the following equations:

$$
y=\frac{A_{2}-A_{1}}{1+e^{\frac{t-t_{0}}{d x}}}+A 1
$$

Equation 1

$$
t_{\text {lag }}=t_{0}-2 d x
$$

\section{Equation 2}

Where $\mathrm{A} 1$ and $\mathrm{A} 2$ represent the initial and maximum fluorescence $\left(F L_{\max }\right)$, $t_{0}$ denotes the time taken to reach half of the maximum fluorescence, $1 / \mathrm{dx}$ is the fibril growth rate constant, and tlag the lag time.

\subsection{Formation of fibrils}

Stock solutions of $\mathrm{G} 48(600 \mu \mathrm{m})$ prepared as above were stored in glass sample tubes at 37 ${ }^{\circ} \mathrm{C}$ and agitated at 250 RPM for the same duration as the kinetic study. Following this, the fibrillated samples were stored at $-24{ }^{\circ} \mathrm{C}$ for further characterisation.

\subsection{Fibrillation inhibition study}

G48, ThT and $\mathrm{NaN}_{3}$ were incubated in a 96 well plate as above, but additionally with the presence of PS80 and/or FA. Wells excluding PS80 or FA acted as positive controls while buffer replaced G48 in the negative control. The final G48 concentration was maintained at $300 \mu \mathrm{M}$ while the final concentrations of PS80 and FA were $25 \mu \mathrm{M}$ and $3 \mathrm{mM}$ respectively. Due to its poor aqueous solubility $(0.7 \mathrm{mg} / \mathrm{mL})$, FA was initially dissolved in DMSO $(10 \mathrm{mg} / \mathrm{mL})$ before being diluted with the appropriate buffer. To examine the formation of fibrils, the same samples were stored in glass tubes at $37^{\circ} \mathrm{C}$ and agitated at 250 RPM for the same duration as the kinetic study but without $\mathrm{ThT}$ and $\mathrm{NaN}_{3}$. Following this, the samples were stored at $-24{ }^{\circ} \mathrm{C}$ for further characterisation.

\subsection{Circular dichroism}

CD spectra of G48 were acquired on a Chirascan Plus spectrometer (Applied Photophysics, Leatherhead, UK). UV and CD analyses were conducted in the regions of $400-230 \mathrm{~nm}$ and $260-200 \mathrm{~nm}$ with $10 \mathrm{~mm}$ and $0.5 \mathrm{~mm}$ Quartz Suprasil rectangular cells (Starna Scientific Ltd, Ilford, UK), respectively. During the experiments, the instrument was flushed continuously with nitrogen gas. Measurements were taken at $1 \mathrm{~nm}$ spectral bandwidth, $1 \mathrm{~nm}$ stepwise and $1 \mathrm{~s}$ accumulation time per point. All measurements were carried out at $23^{\circ} \mathrm{C}$ and both the $\mathrm{UV}$ and CD spectra were buffer corrected. Light scattering correction was applied to the peptide near- 
UV absorption spectrum prior to sample concentration determination. The far-UV CD spectra were normalised for concentration and pathlength, and are presented in terms of mean residue ellipticity (MRE, deg. $\mathrm{cm}^{2} \cdot \mathrm{dmol}{ }^{-1}$ ):

$$
M R E=\frac{M R W * \theta_{o b s}}{10 * l * C}
$$

\section{Equation 3}

Where MRW is the mean residue weight, $\Theta_{\text {obs }}$ represents the ellipticity in millidegrees and $I$ and $C$ are the cell pathlength and peptide concentration, respectively. Data processing was performed using APL Prodata Viewer (Leatherhead, UK). The Bestsel secondary structure prediction analysis tool was used to determine the percentage distribution of secondary structure [20].

\subsection{Peptide quantification}

Peptide quantification was carried out by RP-HPLC on an Agilent 1100 instrument (Cheadle, UK) equipped with a Supelco Biowide C18 column $(4.6 \mathrm{~mm} \times 150 \mathrm{~mm} \times 5 \mu \mathrm{m})$. Initially the samples were centrifuged at 14,000 RPM for 10 min, then the resulting supernatant was withdrawn and diluted with the relevant buffer before analysis. The eluents were HPLC grade (A) water with $0.1 \%$ TFA and (B) acetonitrile with $0.1 \%$ TFA. A gradient method was used as follows: 0-4 mins $30 \%$ B, $4-5.5$ mins linear gradient to $60 \%$ B, $7.5-9.5$ min linear gradient of $B$ down to $30 \%$, followed by a $3.5 \mathrm{~min}$ washout period; the total run time was $13 \mathrm{~min}$. The peptide content was determined by UV absorbance at $214 \mathrm{~nm}$ and a retention time of $7.9 \mathrm{~min}$.

\subsection{Atomic force microscopy}

The fibrillated peptide samples $(20 \mu \mathrm{L})$ were pipetted onto freshly cleaved SPI Supplies mica (West Chester, Pennsylvania, USA) and incubated for $15 \mathrm{~min}$ before being washed with HPLC grade water $(100 \mu \mathrm{L})$ and allowed to dry. AFM analysis was performed with a Dimension FastScan AFM (Bruker, Coventry, UK) equipped with a cantilever operating between 20-100 $\mathrm{Hz}$. The images were analysed with the Bruker AutoMET software.

\subsection{Transmission electron microscopy}

Samples of the fibrillated peptide $(10 \mu \mathrm{L})$ were spotted onto a SPI Supplies copper TEM grid and allowed to incubate for 30 minutes. Following this, $0.22 \mu \mathrm{m}$ filtered $1 \%$ uranyl formate solution was used as a staining agent. The samples were imaged on a Philips/FEI CM120 Bio Twin instrument (Hillsboro, Oregon, USA) operating at $60 \mathrm{kV}$.

\subsection{Dynamic light scattering}

Freshly prepared peptide or fibrillated G48 samples were diluted 1:100 with the corresponding $\mathrm{pH}$ buffer. Size measurements of the samples were performed on a Malvern Instruments 
Zetasizer Nano ZS90 (Malvern, UK). Using a disposable UV cuvette (Brand, Wertheim, Germany), measurements were taken at a fixed scattering angle of $173^{\circ}$ and temperature of $25^{\circ} \mathrm{C}$, with 2 min equilibration before each run. The samples were measured in triplicate with 12 runs per measurement. The fibrillated samples were not filtered further before measurement.

\section{Results and discussion}

\subsection{G48 aggregation kinetics}

Peptide aggregates are associated with reduced efficacy and increased toxicity [6, 7]. It is well established that fibrillation is a multifactorial process with temperature, agitation, peptide concentration and other factors all playing a role [13]. Here, we have sought to understand the influence of $\mathrm{pH}$ and concentration on the aggregation mechanism of a therapeutically relevant 29mer polypeptide, employing the widely used ThT fluorescence assay [12]. The ThT dye binds specifically to the $\beta$-sheet rich structures that are formed when peptides aggregate, which markedly increases the excitation (385 $\rightarrow 450 \mathrm{~nm}$ ) and emission maxima (445 $\rightarrow 482$ $\mathrm{nm})[12]$.

In insulin fibril growth studies, Fodera et al. [21] reported effectively no change in maximum fluorescence $\left(F L_{\max }\right)$ at ThT concentrations ranging from 20-100 $\mu \mathrm{M}$. Thus, our study focused on a ThT concentration in the middle of that range. Temperature increases fibrillation rates [22], and therefore here we conducted experiments at the physiological temperature, to aid understanding of the propensity of the peptide to fibrillate when used by patients as a long acting depot formulation, for example. Agitation is also known to influence fibrillation by increasing fibril breakage and also increasing the air-water interface area [11, 22]. Further, agitation provides a means of stress-testing realistic handling conditions for a peptide formulation. The conditions chosen here are likely to provide the required stress to promote fibril growth in a short timeframe, but are not extreme enough to cause a loss of secondary structure and immediately denature the peptide. Concentrations up to $600 \mu \mathrm{M}$ are being considered for the formulation of G48 and have therefore been explored. The $\mathrm{pH}$ values investigated were chosen to explore the fibrillation properties of G48 at acidic ( $\mathrm{pH} 3.7$ ), physiological $(\mathrm{pH} 7.4)$ and slightly basic $\mathrm{pH}$ conditions $(\mathrm{pH}$ 8.5). The acidic and basic conditions reflect $\mathrm{pH}$ values that are being examined to formulate $\mathrm{G} 48$. In order to ensure that the overall charge of the solutions was not altered by change in $\mathrm{pH}$, at the end of the study, the $\mathrm{pH}$ of each well was tested and confirmed to be the same the starting $\mathrm{pH}$.

The kinetic data obtained at all pH values (Figure 1, Table S1) depict typical sigmoidal curves attributable to peptide fibril growth [12]. At pH 3.7, despite exposure to aggregatory 
inset), show that $F L_{\max }$ correlates positively with concentration. At $\mathrm{pH} 7.4$ and 8.5, a similar correlation in $F L_{\max }$ and concentration can also be seen (Figure 1D,G). It should be noted that at $\mathrm{pH} 3.7$ carrying out the study for a longer period of time (8 days) did not result in the welldefined plateau seen at the other two $\mathrm{pH}$ values.

\section{Figure 1}

The lag time (Figure 1B,E,H), although a period of minimal fluorescence signal, represents a period of stochastic formation of nuclei as well as fibril formation up to a detectable level $[9,13,22]$. Thus, when peptides are seeded with preformed fibril, a marked reduction in lag time ensues [11]. In nucleation-dependent polymerisation, it is expected that at higher concentrations the greater monomeric content should result in a reduction in lag time $[9,13,22]$. However, at $\mathrm{pH} 3.7$ the plot of lag time and concentration (Figure 1B) reveals an increase in lag time with concentration, indicative of an off-pathway mechanism [15, 23] where at higher concentration there is a conversion of initially formed oligomers back to monomeric units, which results in a longer tiag. Deva et al. [23] conducted a study at a similarly low $\mathrm{pH}(\mathrm{pH}$ 2) and propose a similar off-pathway mechanism. The reversal seen is attributable to the formation of amorphous aggregates rather than fully defined fibrils.

To confirm if G48 formed $\beta$ sheet rich aggregates in a nucleation-dependent manner, the peptide was seeded with preformed fibrils. Figure $1 F, I$ reveal a marked reduction in $t_{1 / 2}$ at $\mathrm{pH} 7.4$ (14.9 h vs $5.9 \mathrm{~h}$ ) and 8.5 (22.8 h vs $4.1 \mathrm{~h}$ ), which can be attributed to the acceleration of aggregation in the presence of nuclei from preformed fibrils. However, at $\mathrm{pH} 3.7$ (Figure 1C) there was negligible increase in the fluorescence in the presence of pre-formed seeds. This, along with the $\mathrm{t}_{\mathrm{lag}}$ plots, confirms that the aggregation of $\mathrm{G} 48$ at $\mathrm{pH} 3.7$ was via an off-pathway. Deva et al described similar results on off-pathway kinetics where seeding abrogated fluorescence.

Theoretically, a peptide would aggregate maximally at its pl where the net charge is 0 . The pl of G48 is 5. At pH 3.7, G48 is estimated to have an overall positive net charge (+4). The low $\mathrm{FL}_{\max }$ seen at $\mathrm{pH} 3.7$ could be attributed to strong charge repulsion between peptide monomers and thence a reduced propensity for aggregation. Owczarz et al [24] have reported a similar relationship between net charge and fibril formation with the amphiphilic peptide RADA 16-I. However, insulin, which has a similar pl (5.4), has been reported to fibrillate readily at acidic $\mathrm{pH}$ [22]. This is attributed to the fact that insulin moves from an hexameric to a monomeric state at acidic $\mathrm{pH}$, and as described above monomers are preferential for the propagation (i.e. growth phase) of fibrils. G48 does not form hexamers and at $\mathrm{pH} 3.7$ its charged monomers $(+4)$ in their native conformation appeared to repel one another, reducing aggregated content and thus $\mathrm{FL}_{\max }$. In the absence of any further variable besides $\mathrm{pH}$ the data 
strongly suggest that electrostatics have a major influence [25] in the fibrillation propensity of G48.

At $\mathrm{pH} 7.4$ the $\mathrm{FL}_{\max }$ (Figure 1D) was higher than at $\mathrm{pH} 3.7$, although a similar

262

263

264

265

266

267

268

269

270

271

272

273

274

275

276

277

278

279

280

281

282

283

284

285

286

287

288

289

290

291

292 concentration dependent increase was observed. An inverse correlation $\left(R^{2}=0.6\right)$ was observed between lag time and peptide G48 concentration (Figure 1E). This aligns with the majority of the published literature on fibrillation and suggests a nucleation-dependent polymerisation process where monomer driven formation of nuclei determines the lag period, such that higher concentration results in shorter lag times [13, 22].

At pH 7.4 the peptide net charge of $\mathrm{G} 48$ is estimated to be -2 , and therefore the extent of charge-charge repulsion between peptide monomers is reduced compared to those at $\mathrm{pH}$ 3.7, resulting in a greater extent of fibril growth at $\mathrm{pH} 7.4$ and thus higher $F L_{\max }$. The $\mathrm{FL}_{\max }$ values attained from the ThT assay have been attributed to the weight concentration of aggregates present, thus a higher $F L_{\max }$ points towards higher aggregated content [26]. At the end of the study the wells containing $\mathrm{G} 48$ at $\mathrm{pH} 7.4$ contained a cloudy suspension, consistent with extensive fibrillation since this can often result in precipitation [22]. At $\mathrm{pH} 8.5$ the $\mathrm{FL}_{\max }$ (Figure $1 \mathrm{G}$ ) values drop from those seen at $\mathrm{pH} 7.4$ but are higher than $\mathrm{FL}_{\max }$ values attained at $\mathrm{pH}$ 3.7. As with the lower two $\mathrm{pH}$ values, there is correlation between $\mathrm{FL}_{\max }$ and peptide concentration. The lag time (Figure $1 \mathrm{H}$ ) was inversely proportional to concentration $\left(R^{2}=0.9\right.$ ), and in general longer than that observed at $\mathrm{pH}$ 7.4. Once more, the trend support nucleation as the primary mode of fibril formation at $\mathrm{pH} 8.5$. G48 is estimated to carry a net charge of -3 at $\mathrm{pH} 8.5$, increasing the electrostatic repulsion of $\mathrm{G} 48$ monomers compared to $\mathrm{pH} 7.4$ (Figure $1 \mathrm{E})$. However, the net charge of $\mathrm{G} 48$ remained lower than at $\mathrm{pH} 3.7(+4)$ and thus the charge repulsion appeared insufficient to give the low $\mathrm{FL}_{\max }$ which was observed at $\mathrm{pH}$ 3.7.

Taken together, the kinetic data suggest that changes in the overall peptide net charge are capable of markedly influencing the fibrillation mechanism of G48. As with native GLP-1, at $\mathrm{pH} 3.7$ [27], the imidazole in the His residue in $\mathrm{G} 48$ is protonated, whereas at $\mathrm{pH} 7.4$ and $\mathrm{pH} 8.5$ the His imidazole is deprotonated. The difference between $\mathrm{pH} 7.4$ and 8.5 is that in the latter there is a further $\mathrm{N}$ terminus deprotonation. These electrostatic changes appear to influence the fibrillation kinetics of G48 considerably. Fibrillation (and thus $F L_{\max }$ ) is greatest at the $\mathrm{pl}$ of the peptide, and as the $\mathrm{pH}$ moves further away from this $F L_{\max }$ is reduced. An alternate theory could be that fibril growth is more likely to occur when the peptide possesses an overall negative charge. This does not, however, account for the difference in $\mathrm{FL}_{\text {max }}$ observed when two different $\mathrm{pH}$ values ( 7.4 and 8.5 ) which both result in the peptide being negatively charged are investigated. 


\subsection{Secondary structure of G48}

294 Peptides are optically active and capable of absorbing circular polarised light at certain

295

296

297

298

299

300

301

302

303

304

305

306

307

308

309

310

311

312

313

314

315

316

317

318

319

320

321

322

323

324

325

326

327

328 wavelengths, the interpretation of which can provide details on the conformational state of the peptide [28]. Since $C D$ can provide insight into the secondary structure of a peptide, it can be applied in understanding physical instabilities such as aggregation. The influence of $\mathrm{pH}$ on the secondary structure of $\mathrm{G} 48$ samples $(600 \mu \mathrm{M})$ was examined by $\mathrm{CD}$. Before fibrillation (Figure 2A), all the samples exhibited a classical $\alpha$-helix conformation with ellipticity minima at 224 and $212 \mathrm{~nm}$ [28]. At pH 3.7 the minima around $212 \mathrm{~nm}$ is of slightly lower magnitude than at $\mathrm{pH} 7.4$ and 8.5. Upon subjection to aggregatory conditions, across all $\mathrm{pH}$ values there was a shift in the ellipticity minima to $\sim 218 \mathrm{~nm}$ (Figure 2B). This is attributable to twisted $\beta$-sheet content $[28,29]$. Since the ThT fluorescence did not appear to increase upon seeding at $\mathrm{pH}$ 3.7, CD spectra both for unseeded (Figure 2B) and seeded (Figure S1A) experiments were obtained and identical results are seen with and without the presence of pre-formed fibrils.

Figure 2

The magnitude of absorbance at $\mathrm{pH} 7.4$ is markedly lower than at the other two $\mathrm{pH}$ values (Figure 2B), which can be attributed to the loss of free peptide molecules in solution [30]. Although CD can sometimes show poor sensitivity toward $\beta$-sheets, the spectra are consistent with the physical observations in the ThT study (formation of a cloudy suspension). At pH 8.5 the CD spectra depict a transitioning conformation where the minima at $212 \mathrm{~nm}$ appears to be present but of low magnitude. Nonetheless, it is evident there is a difference in the $C D$ spectra of the fibrillated and non-fibrillated samples of $G 48$, showing a transformation from $\alpha$-helix to increasing $\beta$-sheet content.

To determine the proportion of $\alpha$-helix content present after subjection of G48 to aggregatory conditions, the $\mathrm{CD}$ data were analysed with the Bestsel secondary structure analysis tool [20]. This analysis corroborates a depletion in $\alpha$-helical content of $\mathrm{G} 48$ at all pH values studied, while $\beta$-sheet content either increased or stayed the same (Figure $2 \mathrm{C}$ ). At pH 7.4, while there was a considerable drop in $\alpha$-helical content upon fibril formation there was also a marked increase in other conformations including loops, turns and bends. It should be stressed that such analytical tools are theoretical and based on databases of peptides which may aggregate in very different ways to G48. The studies underpinning the calculations may have also been carried out at different conditions compared to the conditions utilised here. Nevertheless, such tools can provide some insight into the aggregation behaviour of peptides [20] and here supports our understanding of G48's aggregation profile.

\subsection{Aggregate morphology}

The data provided by kinetic studies and CD (Figure 1, Figure 2) suggest that the aggregation profile of G48 differed depending on the solution $\mathrm{pH}$. To determine the morphology of the 
aggregates which formed, AFM and TEM were utilised. At pH 3.7, by AFM (Figure 3A) there appear to be some underdeveloped short fibrils $(<50 \mathrm{~nm})$ and amorphous aggregates can be seen throughout the sample. The TEM image (Figure 3B) depicts aggregates and oligomers, with few defined fibrils. At $\mathrm{pH} 7.4$ there are clearly defined fibrils adjoined to each other in the AFM data (Figure 3C). The fibrils appear longer that those seen at $\mathrm{pH} 3.7$ and have a rod-like morphology ( $150 \mathrm{~nm}$ ). There also appear to be multiple areas of amorphous aggregates, especially at the interconnection point between distinct fibrils. The TEM image (Figure 3D) also shows a mix of amorphous aggregates and short, defined, fibrils.

\section{Figure 3}

At pH 8.5 (Figure 3E) there are a small number of long ( $300-500 \mathrm{~nm})$, well-defined rod-like fibrils in the AFM image, with little to no amorphous aggregate visible. TEM (Figure 3F) depicts a similarly long fibril (yellow arrows), but wormlike protofibrils (green arrows) could also be seen distributed around the image. The AFM and TEM images corroborate the kinetic assay as well as the CD data, pointing towards formation of $\beta$-rich aggregates and fibrils at all three $\mathrm{pH}$ values, although the morphology of fibrils formed differed.

\subsection{Soluble peptide quantification and size characterisation}

The conversion of peptide monomers to aggregates is a nucleation process, and there is bound to be an increase in the size distribution of the peptide in solution as soluble aggregates form. DLS was used to confirm the presence of G48 aggregates. Although fibrils are linear and this technique assumes that the materials being investigated adopt a spherical shape [25, 31 , DLS is routinely used for characterising protein aggregates in the literature [32] and can provide a comparative insight into the formation process.

Figure 4A-C depicts volume distribution profiles, which represent the relative volumes of G48 monomers and aggregates within the sample. Before subjection to aggregatory conditions (Figure $4 \mathrm{~A}-\mathrm{C}$, blue), the hydrodynamic radius $(\mathrm{Rh})$ of the peptide at $\mathrm{pH} 3.7, \mathrm{pH} 7.4$ and $\mathrm{pH} 8.5$ was $0.69 \pm 0.12,0.78 \pm 0.10$ and $0.63 \pm 0.15 \mathrm{~nm}$ respectively. Conversely, after fibrillation (Figure 4A-C, red), the Rh increased markedly at all pH values, to $291 \pm 77 \mathrm{~nm}(\mathrm{pH}$ 3.7) $243 \pm 30 \mathrm{~nm}(\mathrm{pH} \mathrm{7.4)}$ and $209 \pm 34 \mathrm{~nm}(\mathrm{pH} 8.5)$. At pH 3.7, the polydispersity index (PDI) was 0.4 whereas the PDI at the two higher $\mathrm{pH}$ values was close to 1 . The increased $\mathrm{Rh}$ and PDI are attributable to G48 aggregation.

\section{Figure 4}

HPLC studies to quantify the presence of soluble monomeric peptide under aggregatory conditions (Figure 4D) reveal that at all $\mathrm{pH}$ values $\mathrm{G} 48$ depletes completely within $72 \mathrm{~h}$, with the fastest depletion occurring at $\mathrm{pH} 7.4$. Within $24 \mathrm{~h}, 94 \pm 1.2 \%$ of the soluble peptide in its monomeric form had depleted at $\mathrm{pH} 7.4$, whereas there was a slower rate of depletion at $\mathrm{pH} 3.7$ and $\mathrm{pH}$ 8.5. This is attributable to slower elongation of the fibrils. For the 
pH 3.7 experiment, we observe depletion of peptide monomers both with and without the presence of pre-formed fibrils (Figure 4D and Figure S1B). The rate of depletion is more rapid in the former case, as would be intuitively expected. The HPLC and DLS data suggest that, irrespective of the $\mathrm{pH}$, once aged $\mathrm{G} 48$ is converted from its monomeric form to aggregates. This raises significant challenges for the clinical use of G48.

\subsection{Fibrillation inhibition}

Having understood the influence of concentration and $\mathrm{pH}$ on the aggregation profile of G48, and recognised that its aggregation propensity could be a major barrier to clinical use, it became pertinent to design stable formulations which would not fibrillate during production, transport, storage or use. To avoid loss of activity, formulation approaches remain an attractive option to inhibit aggregation [2,33]. Unfortunately there are limited reports in the literature exploring formulation aids specifically for prolonging the stability of clinically relevant peptides.

Two of the most widely discussed fibrillating peptides are $\beta$-amyloid and insulin, both of which have shown increased stability in the presence of phenols [16, 34, 35]. Regarding insulin, phenols together with $\mathrm{Zn}^{2+}$ are thought to promote the hexameric conformation and prevent this separating into the monomers which drive fibril growth $[18,36]$. One phenolic molecule which has recently been shown to reduce fibrillation in insulin [16] and glucagon [37] formulations is ferulic acid (FA), an abundant natural molecule. In protein formulations, surfactants are also widely used to provide stability. Surfactants can be either ionic or nonionic, but ionic surfactants are known denaturants of proteins [19]. The use of non-ionic surfactants such as polysorbate 80 (PS80) to reduce fibrillation in peptide formulations is sparsely described [37, 38].

ThT fluorescence studies were performed in the presence of FA or PS80 (Figure 5). At pH 3.7 (Figure $5 \mathrm{~A}$ ) the addition of $F A$ to $\mathrm{G} 48$ increased $\mathrm{FL}_{\max }$, suggesting a higher level of $\beta$-sheet content than with $\mathrm{G} 48$ only. Although the difference in $\mathrm{FL}_{\max }$ was not excessive, this was unexpected [37]. A possible explanation may lie in the structural properties of FA. The ionisable carboxyl group ( $\mathrm{pKa} \sim 4$ ) is thought to play a role in the interaction of $F A$ with peptides [16], and this being unionised at pH 3.7 may have affected FA interaction with G48.

\section{Figure 5}

PS80 completely suppresses any fibrillation at $\mathrm{pH} 3.7$, and does so even when FA was present (Figure 5A). As PS80 is non-ionic, its mechanism for inhibiting fibril formation is not thought to be through binding interactions [39], but rather through reduction of the air-solution interface, which is a known culprit in peptide and protein aggregation [40]. PS80 is amphiphilic, and thus able to outcompete the peptide at these interfaces [41] and reduce fibril formation.

At $\mathrm{pH} 7.4$, unlike at $\mathrm{pH} 3.7$, adding $\mathrm{FA}$ to $\mathrm{G} 48$ reduced the $\mathrm{FL}_{\max }$ (Figure 5B), although this reduction is marginal and fibrillation still occurs. With the addition of PS80, fibril growth is 
completely halted. The same results were seen when PS80 is added to solutions containing

402 FA. At pH 8.5 (Figure 5C) the addition of FA to G48 increased the lag time (to $55+0.1 \mathrm{~h}$ ) but 403 did not completely halt fibrillation, whereas with PS80 once again the data suggest no

404

405

406

407

408

409

410

411

412

413

414

415

416

417

418

419

420

421

422

423

424

425

426

427

428

429

430

431

432

433

434

435

436 fibrillation occurred.

The peptide concentration used $(300 \mu \mathrm{M}, 1 \mathrm{mg} / \mathrm{mL})$ represents roughly twice the concentration of the most widely known GLP-1 formulation in the clinic (exenatide; $112 \mu \mathrm{M}$, $500 \mu \mathrm{g} / \mathrm{mL}$ ). This concentration for $\mathrm{G} 48$ was chosen in order mirror a realistic clinical product. Jayamani et al. [16] were able to suppress insulin fibril formation at a similar peptide:FA molar ratio as used in this study (1:10). Bakhtiani et al. [37] also report that FA eliminated fibril formation in glucagon $(300 \mu \mathrm{M})$, but their formulation included both FA (1 mM, 1:3) and PS80 $(500 \mu \mathrm{M}, \sim 1: 2)$, and so it is unclear if $\mathrm{FA}$ alone was capable of eliminating glucagon fibrillation. PS80 concentrations of up to $1 \mathrm{mM}$ have previously been used in albumin and antibody stability studies [42, 43]. Here, in an attempt to minimise the use of additives, much lower concentrations of PS80 were utilised $(25 \mu \mathrm{M}, \sim 10: 1)$ and it was observed that even at such low concentrations PS80 was capable of suppressing fibrillation.

Overall, in contrast to G48 alone (Figure $1 \mathrm{cf}$. Figure 5), the data confirm reduced fibrillation of the peptide when it is combined with PS80. In order for FA to play a similar role and completely halt fibrillation, a higher concentration may be needed.

\subsection{Soluble peptide quantification and secondary structure of G48 formulations}

Having demonstrated the ability to influence the kinetics of fibril growth, the role of FA and PS80 in maintaining the conformation of peptide G48 was investigated. Owing to the extensive absorbance of FA in the far-UV region (200 - $240 \mathrm{~nm}$ ) [16], CD analysis was precluded as the data obtained suggest an obstruction of the G48 signal and were not meaningful. With PS80 (Figure 6) the CD data are consistent with the maintenance of the $\alpha$-helical conformation under the same aggregatory conditions which cause G48 alone to fibrillate (Figure $2 B$ ), with ellipticity minima at 212 and $224 \mathrm{~nm}$ at all $\mathrm{pH}$ values. Interestingly, there appeared to be a slight increase in helicity at $\mathrm{pH} 3.7$, evidenced by the more prominent minimum at $212 \mathrm{~nm}$. The Bestsel tool also confirmed that the $\alpha$-helical conformation remained constant across all $\mathrm{pH}$ values (Figure 6C) in the presence of PS80. This corroborates with the kinetic data (Figure 5) which shows negligible $F L_{\max }$ in the presence of PS80. It is thought that PS80 outcompetes G48 at the air-water interface to suppress G48 fibril formation.

\section{Figure 6}

In the absence of stabilisers to inhibit fibril formation, there was complete loss of soluble monomeric G48 in solution within $72 \mathrm{~h}$ at all $\mathrm{pH}$ values (Figure 4D). When PS80 was included, there was negligible to no depletion of monomeric G48 in solution at all three $\mathrm{pH}$ 
437 values over the same time period (Figure 7A). This corroborates the lack of fibril formation 438 shown by the combination of CD and ThT assay data. On inclusion of FA as an additive in the 439 peptide solution, there was a gradual but incomplete reduction in soluble monomeric peptide 440 according to the HPLC data (Figure 7B). The data hence suggest that FA was capable of 441 inhibiting fibrillation but to a lesser extent than PS80. DLS experiments were additionally 442 performed, but the size distribution of G48 with PS80 before and after aggregation remained 443 the same and is suggestive of the presence of micelles rather aggregates. As such, the data have been excluded.

\section{Figure 7}

\subsection{Excipient influence on G48 aggregate morphology}

447 The influence of the two formulation additives on inhibiting G48 fibrillation was investigated 448 further by AFM. At all three $\mathrm{pH}$ values no fibrillar structures can be seen when PS80 is added 449 to the G48 solution, although a few small non-uniform aggregates appear to be present (Figure $4508 \mathrm{~A}, \mathrm{C}$ and $\mathrm{E}$ ). These images are in dramatic contrast to those observed in the absence of the surfactant (Figure 3). When FA was added to a solution of G48, well-defined fibrils (500 nm) were formed at $\mathrm{pH} 3.7$ (Figure $8 \mathrm{~B}$ ), although there appeared to be lower amounts of amorphous aggregates in comparison to G48 solutions in the absence of FA (Figure 3A). At $\mathrm{pH} 7.4$ multiple short rope-like fibrillar structures $(100 \mathrm{~nm})$ can be seen as well as some amorphous aggregates (Figure 8D), while at pH 8.5 (Figure 8F) there are a mixture of fibrillar twists which entangle with the amorphous aggregates. The images obtained from AFM corroborate the kinetic and CD data (Figures 5 and 6).

Figure 8

459

460

\section{Conclusion}

462 Our data demonstrate that by formulation with excipients it is possible to inhibit the $\mathrm{pH}$ 463 dependent aggregation profile exhibited by peptide G48. At pH 3.7, below the isoelectric point 464 of $\mathrm{G} 48$ ( $\mathrm{pl} \sim 5$ ), an off-pathway mechanism for aggregation occurred leading to the formation 465 of amorphous aggregates. At $\mathrm{pH}>\mathrm{pl}(\mathrm{pH} 7.4$ and 8.5) a typical nucleation-dependent 466 polymerisation mechanism was observed, resulting in the formation of well-defined fibrils. In addition, owing to charge repulsion, the weight concentration of the fibrils $\left(F L_{\max }\right)$ correlated with the net charge such that $\mathrm{pH}$ values resulting in a higher net charge $(\mathrm{pH} 3.7$ and 8.5) tended to result in reduced fibril growth. While higher net charge demonstrably played a role in the fibrillation kinetics of G48, it may not always be feasible to attain even higher charges to fully suppress fibrillation by charge repulsion, due to these demanding extreme $\mathrm{pH}$ values 
that are unsuitable for clinical use. Another factor which promotes fibrillation is the air-water interface. Consequently, utilising excipients that can efficiently occupy the air-water interface is a more appropriate route to ensure more complete solubilisation of the peptide. Coformulating G48 with the non-ionic surfactant polysorbate 80 (PS80) completely prevented fibril formation while a phenolic co-formulant (ferulic acid) was capable of reducing but not fully suppressing G48 fibrillation.

In the formulation of peptides for clinical use, an understanding of the mechanisms underpinning physical instabilities such as peptide fibrillation are required to help identify appropriate strategies to maintain peptide stability. In this case, the data demonstrate that G48 fibrillates at neutral and slightly basic $\mathrm{pH}$ values but the presence of a co-formulant such as PS80 can completely halt its aggregation.

\section{Acknowledgements}

485

486

487

488

489

490

491

492

493

494

495

496

497

498

499

500

501

502

503

504

505

506

507

508

509

510

511

512

RE thanks the EPSRC for funding in the form of a studentship under the EPSRC Centre for Doctoral Training in Targeted Therapeutics and Nanomedicines (EP/L01646X/1). The authors also thank AstraZeneca for donation of the peptide used in this study and Isabel Gonçalves for her contribution towards the fluorescence assays.

\section{References}

1. Lau, J.L. and M.K. Dunn, Therapeutic peptides: Historical perspectives, current development trends, and future directions. Bioorg Med Chem, 2017.

2. Wang, W. and C.J. Roberts, Protein aggregation - Mechanisms, detection, and control. Int J Pharm, 2018. 550(1-2): p. 251-268.

3. Hamley, I.W., Peptide fibrillization. Angew Chem Int Ed Engl, 2007. 46(43): p. 812847.

4. Chapman, M.R., L.S. Robinson, J.S. Pinkner, R. Roth, J. Heuser, M. Hammar, S. Normark, and S.J. Hultgren, Role of Escherichia coli curli operons in directing amyloid fiber formation. Science, 2002. 295(5556): p. 851-5.

5. Rambaran, R.N. and L.C. Serpell, Amyloid fibrils: abnormal protein assembly. Prion, 2008. 2(3): p. 112-7.

6. Nilsson, M.R., Insulin amyloid at injection sites of patients with diabetes. Amyloid, 2016. 23(3): p. 139-147.

7. Demeule, B., R. Gurny, and T. Arvinte, Where disease pathogenesis meets protein formulation: renal deposition of immunoglobulin aggregates. Eur J Pharm Biopharm, 2006. 62(2): p. 121-30.

8. Lundmark, K., G.T. Westermark, A. Olsén, and P. Westermark, Protein fibrils in nature can enhance amyloid protein A amyloidosis in mice: Cross-seeding as a disease mechanism. Proceedings of the National Academy of Sciences, 2005. 102(17): p. 6098-6102.

9. Arosio, P., T.P. Knowles, and S. Linse, On the lag phase in amyloid fibril formation. Phys Chem Chem Phys, 2015. 17(12): p. 7606-18. 
513 10. Pedersen, J.S., The nature of amyloid-like glucagon fibrils. J Diabetes Sci Technol, 2010. 4(6): p. 1357-67.

11. Shvadchak, V.V., M.M. Claessens, and V. Subramaniam, Fibril breaking accelerates alpha-synuclein fibrillization. J Phys Chem B, 2015. 119(5): p. 1912-8.

12. Biancalana, M. and S. Koide, Molecular mechanism of Thioflavin-T binding to amyloid fibrils. Biochim Biophys Acta, 2010. 1804(7): p. 1405-12.

13. Zapadka, K.L., F.J. Becher, A.L. Gomes Dos Santos, and S.E. Jackson, Factors affecting the physical stability (aggregation) of peptide therapeutics. Interface Focus, 2017. 7(6): p. 20170030.

14. Moriarty, G.M., M.P. Olson, T.B. Atieh, M.K. Janowska, S.D. Khare, and J. Baum, A $\mathrm{pH}$-dependent switch promotes beta-synuclein fibril formation via glutamate residues. J Biol Chem, 2017. 292(39): p. 16368-16379.

15. Zapadka, K.L., F.J. Becher, S. Uddin, P.G. Varley, S. Bishop, A.L. Gomes Dos Santos, and S.E. Jackson, $A$ pH-Induced Switch in Human Glucagon-like Peptide-1 Aggregation Kinetics. J Am Chem Soc, 2016. 138(50): p. 16259-16265.

16. Jayamani, J., G. Shanmugam, and E.R. Azhagiya Singam, Inhibition of insulin amyloid fibril formation by ferulic acid, a natural compound found in many vegetables and fruits. RSC Adv., 2014. 4(107): p. 62326-62336.

17. Stigsnaes, P., S. Frokjaer, S. Bjerregaard, M. van de Weert, P. Kingshott, and E.H. Moeller, Characterisation and physical stability of PEGylated glucagon. Int J Pharm, 2007. 330(1-2): p. 89-98.

18. Teska, B.M., J. Alarcon, R.J. Pettis, T.W. Randolph, and J.F. Carpenter, Effects of phenol and meta-cresol depletion on insulin analog stability at physiological temperature. J Pharm Sci, 2014. 103(8): p. 2255-67.

19. Frokjaer, S. and D.E. Otzen, Protein drug stability: a formulation challenge. Nat Rev Drug Discov, 2005. 4(4): p. 298-306.

20. Micsonai, A., F. Wien, L. Kernya, Y.H. Lee, Y. Goto, M. Refregiers, and J. Kardos, Accurate secondary structure prediction and fold recognition for circular dichroism spectroscopy. Proc Natl Acad Sci U S A, 2015. 112(24): p. E3095-103.

21. Fodera, V., F. Librizzi, M. Groenning, M. van de Weert, and M. Leone, Secondary nucleation and accessible surface in insulin amyloid fibril formation. J Phys Chem B, 2008. 112(12): p. 3853-8.

22. Nielsen, L., R. Khurana, A. Coats, S. Frokjaer, J. Brange, S. Vyas, V.N. Uversky, and A.L. Fink, Effect of Environmental Factors on the Kinetics of Insulin Fibril Formation: Elucidation of the Molecular Mechanismt. Biochemistry, 2001. 40(20): p. 6036-6046.

23. Deva, T., N. Lorenzen, B.S. Vad, S.V. Petersen, I. Thorgersen, J.J. Enghild, T. Kristensen, and D.E. Otzen, Off-pathway aggregation can inhibit fibrillation at high protein concentrations. Biochim Biophys Acta, 2013. 1834(3): p. 677-87.

24. Owczarz, M., T. Casalini, A.C. Motta, M. Morbidelli, and P. Arosio, Contribution of Electrostatics in the Fibril Stability of a Model Ionic-Complementary Peptide. Biomacromolecules, 2015. 16(12): p. 3792-801.

25. Dokouhaki, M., A. Hung, L. Day, and S.L. Gras, The pH-dependent assembly of Chaplin E from Streptomyces coelicolor. J Struct Biol, 2017. 198(2): p. 82-91.

26. Groenning, M., L. Olsen, M. van de Weert, J.M. Flink, S. Frokjaer, and F.S. Jørgensen, Study on the binding of Thioflavin $T$ to $\beta$-sheet-rich and non- $\beta$-sheet cavities. Journal of Structural Biology, 2007. 158(3): p. 358-369.

27. Ahren, B., GLP-1 for type 2 diabetes. Exp Cell Res, 2011. 317(9): p. 1239-45.

28. Kelly, S.M., T.J. Jess, and N.C. Price, How to study proteins by circular dichroism. Biochim Biophys Acta, 2005. 1751(2): p. 119-39.

29. Greenfield, N.J., Using circular dichroism spectra to estimate protein secondary structure. Nat Protoc, 2006. 1(6): p. 2876-90.

30. Greenfield, N.J., Applications of circular dichroism in protein and peptide analysis. TrAC Trends in Analytical Chemistry, 1999. 18(4): p. 236-244. 
31. Stetefeld, J., S.A. McKenna, and T.R. Patel, Dynamic light scattering: a practical guide and applications in biomedical sciences. Biophys Rev, 2016. 8(4): p. 409-427.

569

32. Rowe, J.B., R.P. Flynn, H.R. Wooten, H.A. Noufer, R.A. Cancel, J. Zhang, J.A. Subramony, S. Pechenov, and Y. Wang, Submicron Aggregation of Chemically Denatured Monoclonal Antibody. Mol Pharm, 2018. 15(10): p. 4710-4721.

33. Swierczewska, M., K.C. Lee, and S. Lee, What is the future of PEGylated therapies? Expert Opin Emerg Drugs, 2015. 20(4): p. 531-6.

34. Ono, K., K. Hasegawa, H. Naiki, and M. Yamada, Curcumin has potent antiamyloidogenic effects for Alzheimer's beta-amyloid fibrils in vitro. J Neurosci Res, 2004. 75(6): p. 742-50.

35. lannuzzi, C., M. Borriello, G. Irace, M. Cammarota, A. Di Maro, and I. Sirangelo, Vanillin Affects Amyloid Aggregation and Non-Enzymatic Glycation in Human Insulin. Sci Rep, 2017. 7(1): p. 15086.

36. Brader, M.L., N.C. Kaarsholm, R.W.K. Lee, and M.F. Dunn, Characterization of the rstate insulin hexamer and its derivatives. The hexamer is stabilized by heterotropic ligand binding interactions. Biochemistry, 1991. 30(27): p. 6636-6645.

37. Bakhtiani, P.A., N. Caputo, J.R. Castle, J. El Youssef, J.M. Carroll, L.L. David, C.T. Roberts, Jr., and W.K. Ward, A novel, stable, aqueous glucagon formulation using ferulic acid as an excipient. J Diabetes Sci Technol, 2015. 9(1): p. 17-23.

38. Caputo, N., M.A. Jackson, J.R. Castle, J. El Youssef, P.A. Bakhtiani, C.P. Bergstrom, J.M. Carroll, M.E. Breen, G.L. Leonard, L.L. David, C.T. Roberts, Jr., and W.K. Ward, Biochemical stabilization of glucagon at alkaline pH. Diabetes Technol Ther, 2014. 16(11): p. 747-58.

39. McAuley, W.J., D.S. Jones, and V.L. Kett, Characterisation of the Interaction of Lactate Dehydrogenase With Tween-20 Using Isothermal Titration Calorimetry, Interfacial Rheometry and Surface Tension Measurements. Journal of Pharmaceutical Sciences, 2009. 98(8): p. 2659-2669.

40. Chang, B.S., B.S. Kendrick, and J.F. Carpenter, Surface-Induced Denaturation of Proteins during Freezing and its Inhibition by Surfactants. Journal of Pharmaceutical Sciences, 1996. 85(12): p. 1325-1330.

41. Singh, S.M., S. Bandi, D.N.M. Jones, and K.M.G. Mallela, Effect of Polysorbate 20 and Polysorbate 80 on the Higher-Order Structure of a Monoclonal Antibody and Its Fab and FC Fragments Probed Using 2D Nuclear Magnetic Resonance Spectroscopy. J Pharm Sci, 2017. 106(12): p. 3486-3498.

42. Arakawa, T. and Y. Kita, Protection of Bovine Serum Albumin from Aggregation by Tween 80. Journal of Pharmaceutical Sciences, 2000. 89(5): p. 646-651.

43. Joshi, V., T. Shivach, N. Yadav, and A.S. Rathore, Circular dichroism spectroscopy as a tool for monitoring aggregation in monoclonal antibody therapeutics. Anal Chem, 2014. 86(23): p. 11606-13. 


\section{Figure Legends}

609

610 Figure 1 The aggregation kinetics of $G 48$ at $(A, B, C) p H ~ 3.7,(D, E, F) p H ~ 7.4$ and $(G, H, I) p H$

6118.5 , as investigated by ThT fluorescence assay. On the left hand side $(A, D, G)$, the change in

612 fluorescence with time is plotted for concentrations of $\mathrm{G} 48$ ranging from $0 \mu \mathrm{M}-600 \mu \mathrm{M}$. The

613 middle panel $(\mathrm{B}, \mathrm{E}, \mathrm{H})$ shows the lag time obtained by fitting a sigmoidal equation (Equation 1 ,

614 2) to the raw data. On the right hand panel (C,F,I), the changes in fluorescence when $G 48$

$615(150 \mu \mathrm{M})$ is seeded with pre-formed fibrils. The data represent triplicate measurements as

616 mean \pm S.D.

617

618 Figure 2 Far-UV CD spectra of peptide $\mathrm{G} 48$ at pH 3.7, 7.4 and 8.5. Measurements recorded

619 (A) before and (B) after fibrillation, and (C) a breakdown of conformation type as determined 620 with the Bestsel secondary structure analysis tool [20]. The experiments were carried out at $62123{ }^{\circ} \mathrm{C}$.

622

623 Figure $3 \mathrm{G} 48$ fibrils formed after exposure to aggregatory conditions for four days at $\mathrm{pH}(\mathrm{A}, \mathrm{B})$ 624 3.7, (C,D) 7.4 and (E,F) 8.5 and imaged by (left hand side) AFM and (right hand side) TEM. 625 The scale bar represents $100 \mathrm{~nm}$ and arrows are included in the TEM images to guide the 626 reader.

627

628 Figure 4 DLS measurements of G48 (blue) before and (red) after fibrillation at pH (A) 3.7 (B) 6297.4 and $(C)$ 8.5.The data of triplicate measurements are given as mean \pm SD and are 630 presented as volume distribution. (D) The percentage of soluble peptide (mean \pm SD) 631 remaining after aggregation for 72 hours.

632

633 Figure 5 The aggregation kinetics of G48 $(300 \mu \mathrm{M})$ with PS80 $(25 \mu \mathrm{M})$ and/or FA $(3 \mathrm{mM})$ acting 634 as co-formulants: (A) $\mathrm{pH} 3.7,(\mathrm{~B}) 7.4,(\mathrm{C})$ 8.5. The data are given as the mean $\pm \mathrm{SD}$ of three 635 independent ThT fluorescence experiments.

636

637 Figure 6 Far UV-CD spectra of peptide G48 formulated with PS80 at pH 3.7, 7.4 and 8.4.

638 Measurements recorded $(A)$ before and $(B)$ after exposure to similar aggregatory conditions 639 (see Figure 1), and (C) the percentage of $\alpha$-helical content as determined by Bestsel 640 secondary structure analysis. The experiments were carried out at $23^{\circ} \mathrm{C}$. The far UV-CD 641 spectra of G48 with FA were not recorded as the magnitude of absorption from FA at the far 642 UV region resulted in artefacts. 
644 Figure 7 Quantification of soluble monomeric G48 formulated with (A) PS80 and (B) FA at pH $6453.7,7.4$ and 8.5. The measurements were carried out by HPLC and the data represent the 646 mean \pm SD of triplicate experiments.

647 Figure 8 AFM images of G48 samples formulated with PS80 at (A) pH 3.7, (C) pH 7.4, (E) pH $648 \quad 8.5$ and FA at (B) pH 3.7 (D) pH 7.4 and (E) pH 8.5. The samples were aged for four days 649 under similar aggregatory conditions. The scale bar represents $400 \mathrm{~nm}$.

650 
A

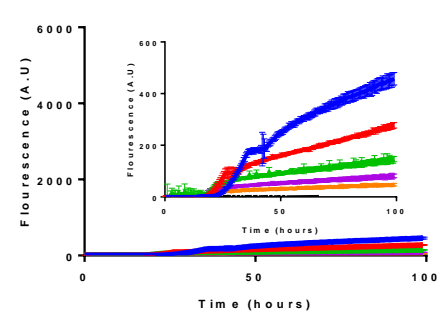

D

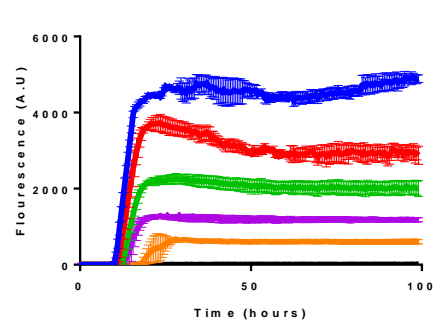

G

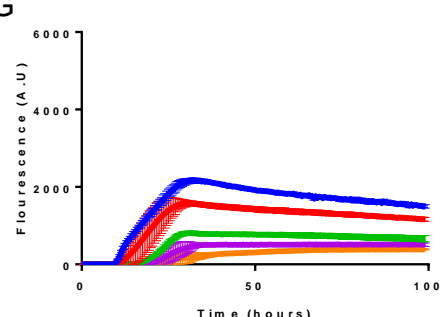

B

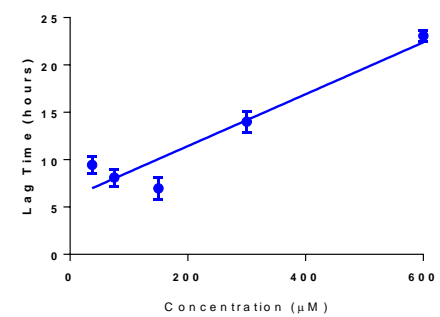

$\mathrm{E}$

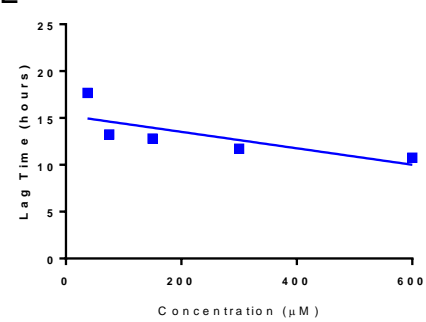

$\mathrm{H}$

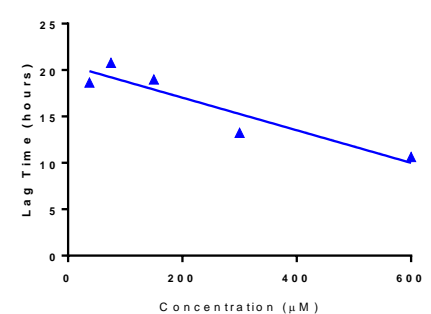

C

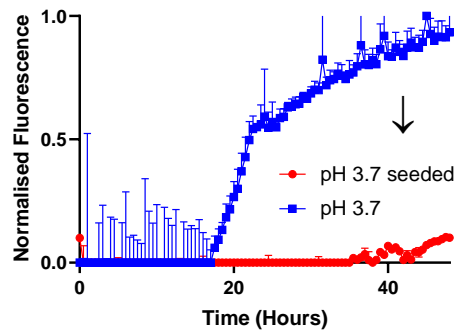

$\mathrm{F}$

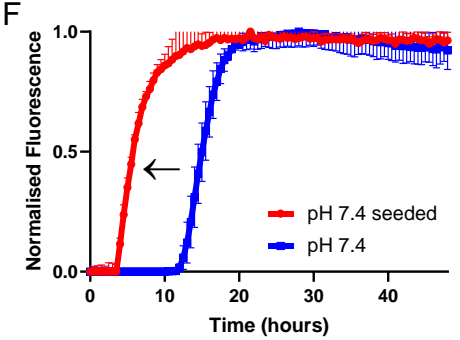

I

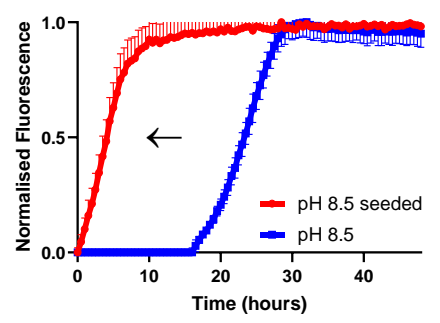

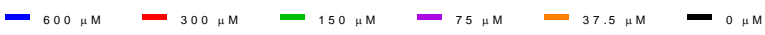

Figure 1 The aggregation kinetics of $G 48$ at $(A, B, C) p H 3.7,(D, E, F) p H 7.4$ and $(G, H, I) p H 8.5$, as investigated by ThT fluorescence assays. On the left hand side $(A, D, G)$, the change in fluorescence with time is plotted for concentrations of G48 ranging from $0 \mu \mathrm{M}-600 \mu \mathrm{M}$. The middle panel $(B, E, H)$ shows the lag time obtained by fitting a sigmoidal equation (Equations 1 and 2) to the raw data. On the right hand panel (C,F,I), the changes in fluorescence when G48 (150 $\mu \mathrm{M})$ is seeded with pre-formed fibrils is depicted. The data represent triplicate measurements as mean \pm S.D. 
A

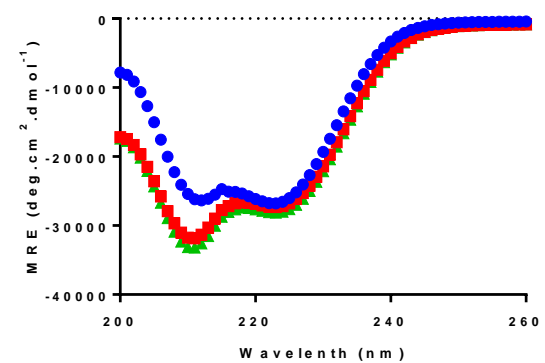

B

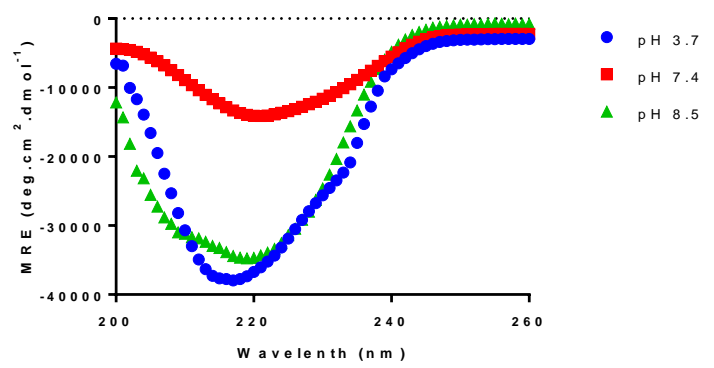

C

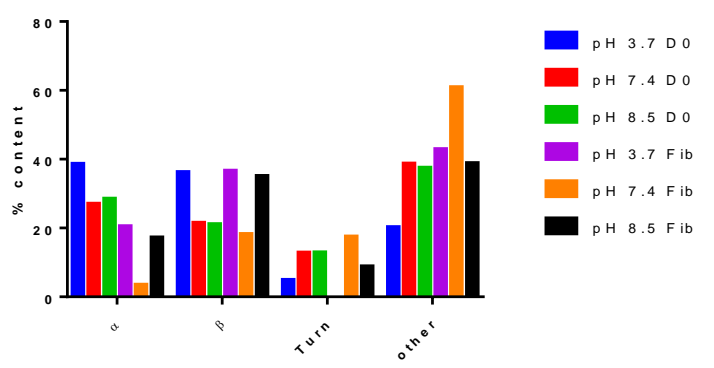

Figure 2 Far-UV CD spectra of peptide G48 at pH 3.7, 7.4 and 8.5. Measurements recorded (A) before and (B) 

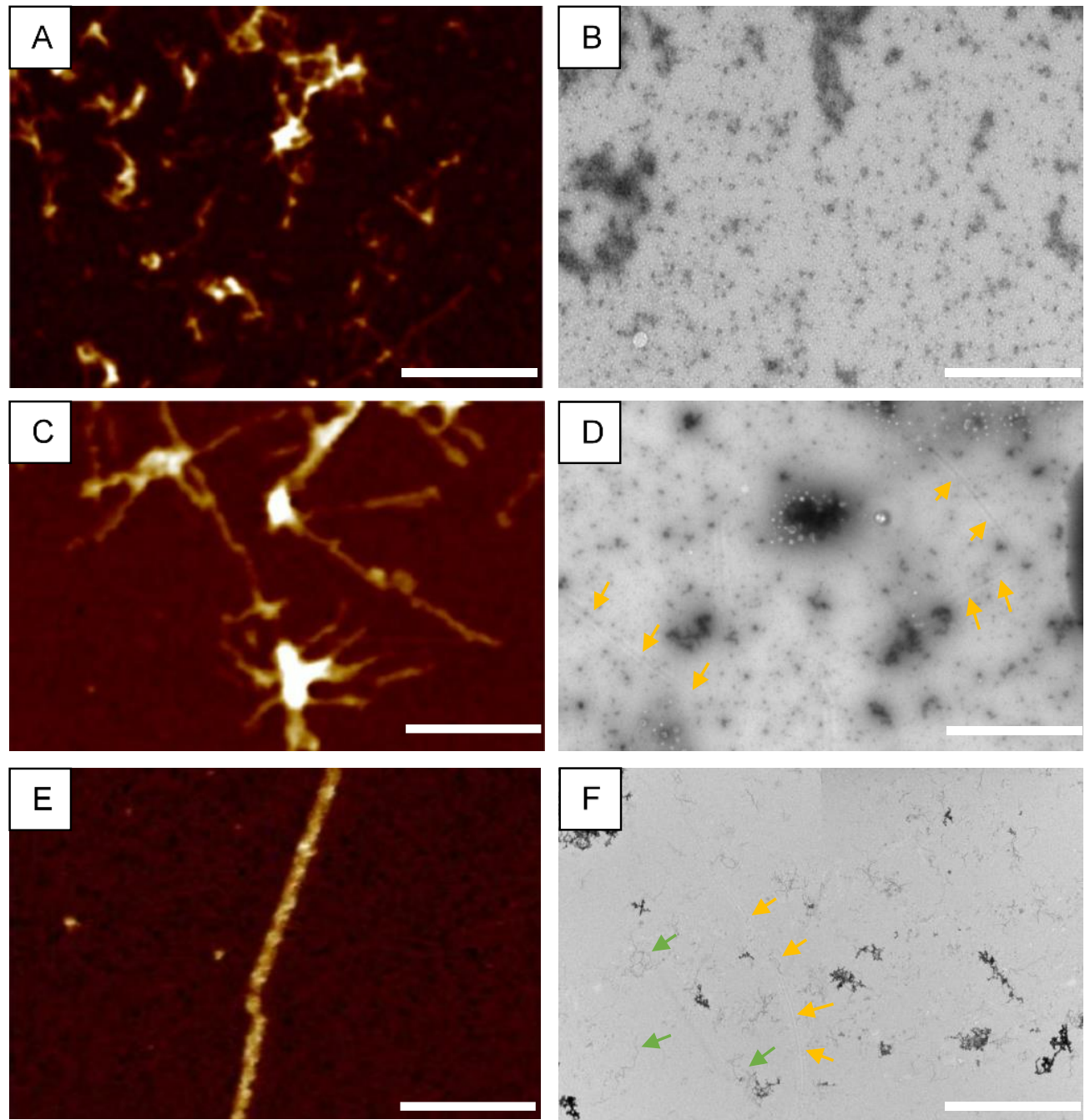

681

682

683

684

685

686

687

688

689

690

691

692

693

694 
A

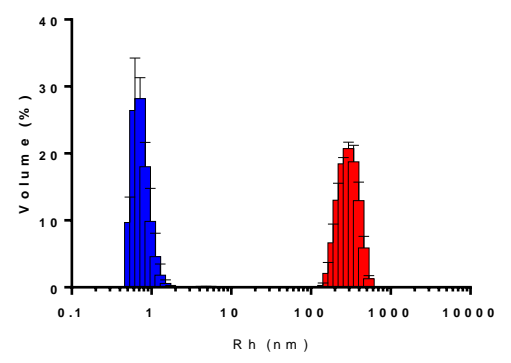

C

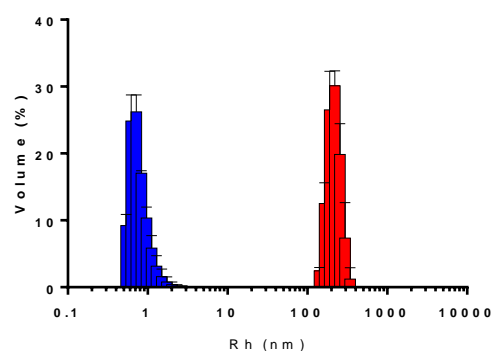

B
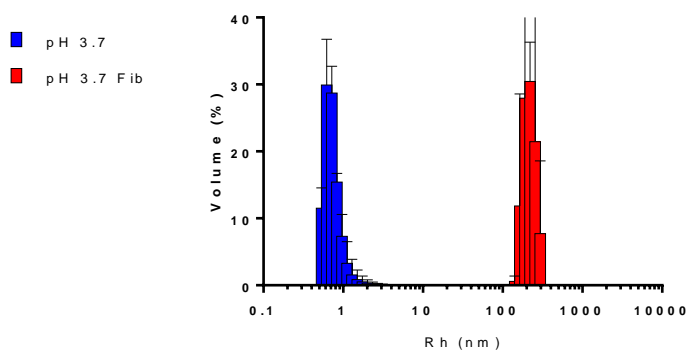

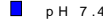

a $\mathrm{pH} 7.4 \mathrm{Fib}$
D

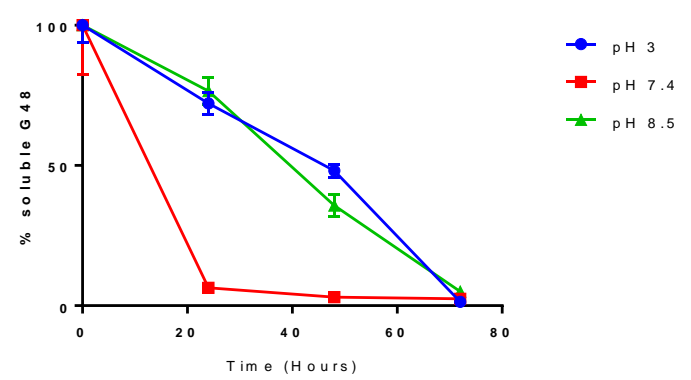

695

696

697

698

699

700

701

702

703

704

705

706

707

708

709

710

711

712

Figure 4 DLS measurements of G48 (blue) before and (red) after fibrillation at $p H(A) 3.7(B) 7.4$ and $(C)$ 8.5.The data represent the average of triplicate measurements $\pm S D$ and are presented as volume distribution. (D) The percentage of soluble peptide $\pm S D$ remaining in solution after aggregation for 72 hours.

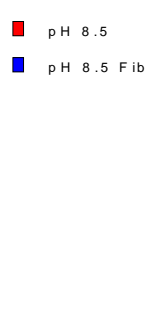

percentage of soluble peptide $\pm S D$ remaining in solution after aggregation for 72 hours. 
716 A

717

718

719

720

721

722

723

724

725

726

727

728

729

730

731

732

733

734

735

736

737

738

739

740

741

742

743

744

745

746

747

748

749
B

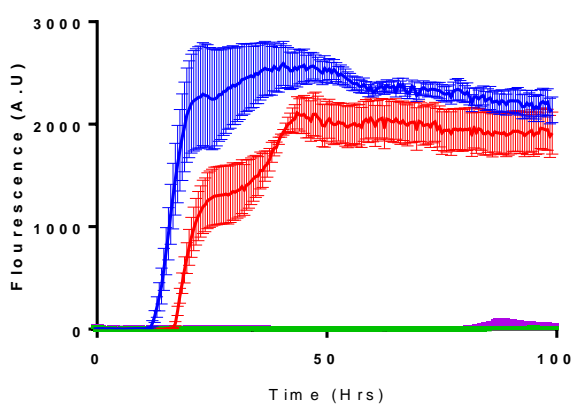

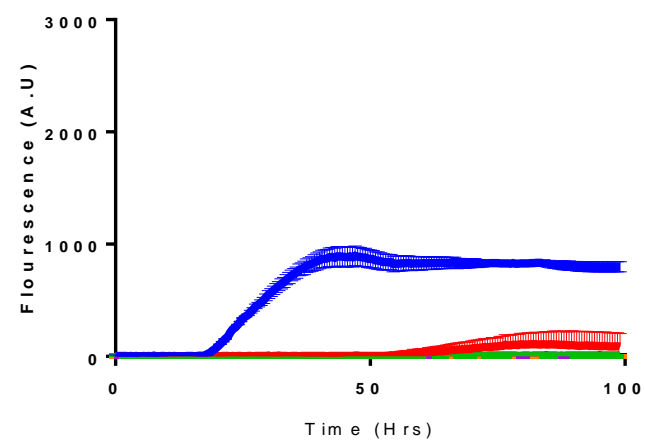

Figure 5 The aggregation kinetics of G48 (300 $\mu \mathrm{M})$ with PS80 (25 $\mu \mathrm{M})$ and/or FA (3 mM) acting as co-formulants: (A) $\mathrm{pH}$ 3.7, (B) 7.4, (C) 8.5. The data are given as the mean $\pm S D$ of three independent $T h T$ fluorescence experiment.

C

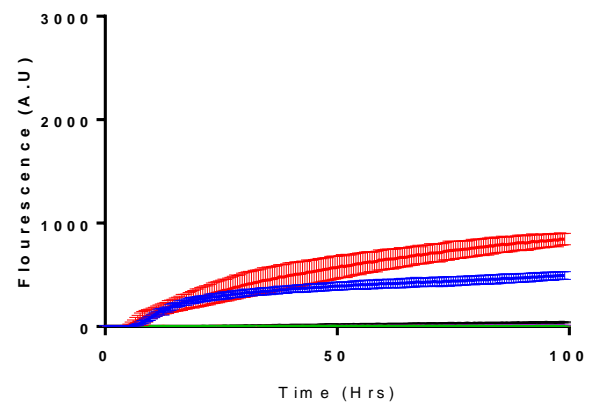


A

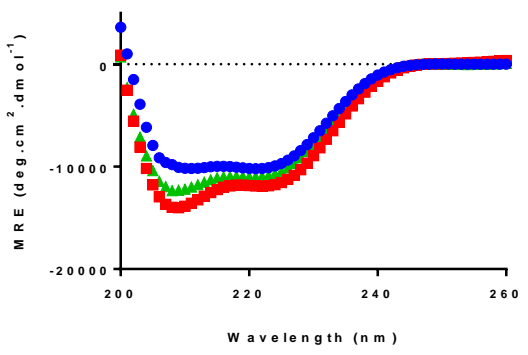

C
B

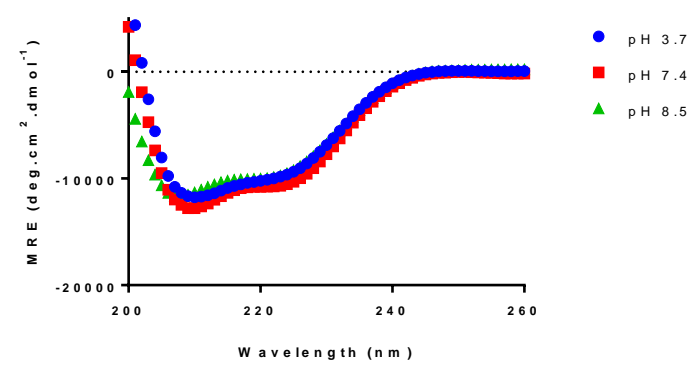

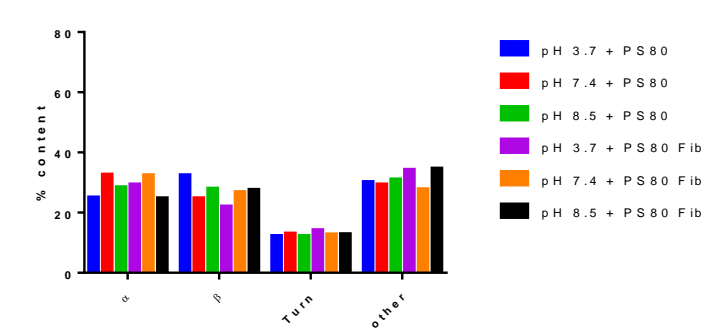

Figure 6 Far UV-CD spectra of peptide G48 formulated with PS80 at pH 3.7, 7.4 and 8.4. Measurements recorded $(A)$ before and $(B)$ after exposure to similar aggregatory conditions (see Figure 1), and (C) the percentage of $\alpha$ helical content as determined by Bestsel secondary structure analysis. The experiments were carried out at $23^{\circ} \mathrm{C}$. The far UV-CD spectra of G48 with FA were not recorded as the magnitude of absorption from FA at the far UV region resulted in artefacts. 
A

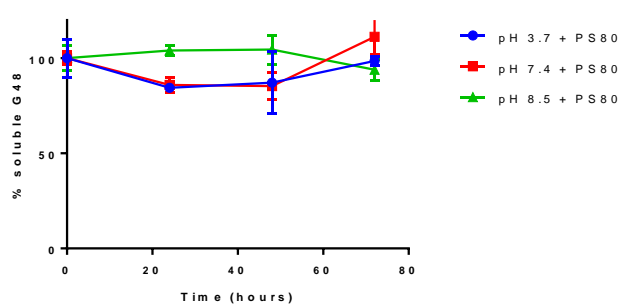

B

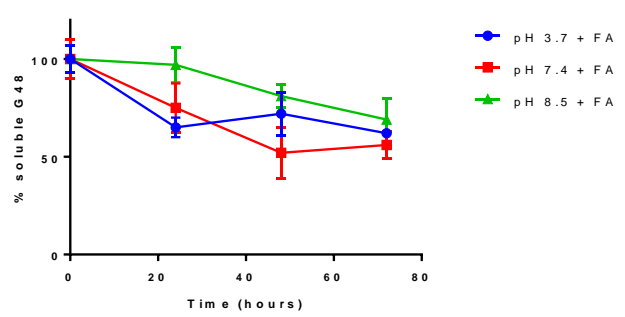

771

772

773

774

775

776

777

778

779

780

781

782

783

784

785

786

787

788

789

790

791

792

793

794

795

796

Figure 7 Quantification of soluble monomeric G48 formulated with (A) PS80 and (B) FA at pH 3.7, 7.4 and 8.5. The measurements were carried out by HPLC and the data represents the mean $\pm S D$ of triplicate experiments. 

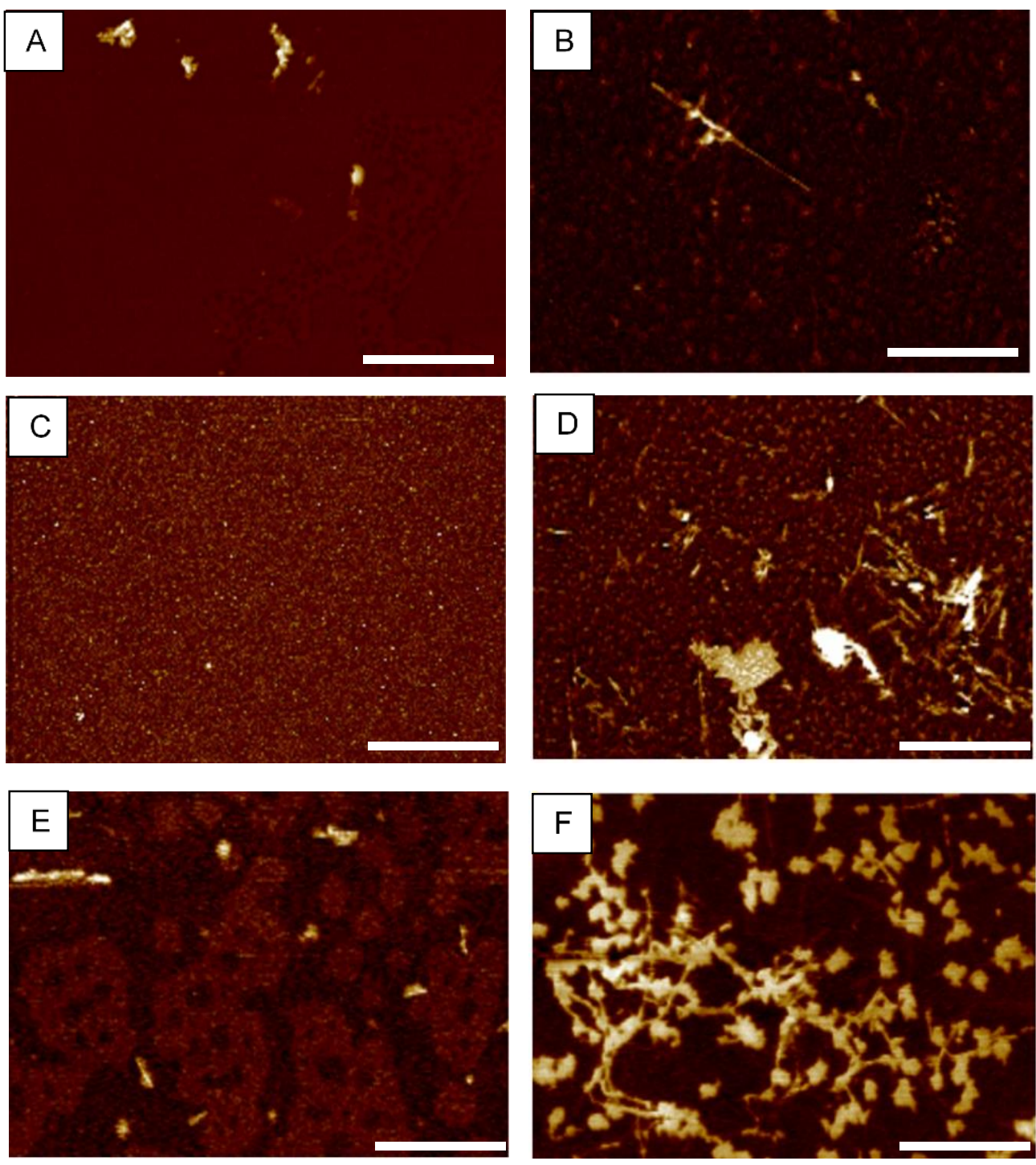

Figure 8 AFM images of G48 samples formulated with PS80 at (A) pH 3.7, (C) pH 7.4, (E) pH 8.5 and FA at (B) pH 799 $3.7(D) p H 7.4$ and $(F) p H$ 8.5. The samples were aged for four days under similar aggregatory conditions. The 800 scale bar represents $400 \mathrm{~nm}$.

801

802 